\title{
Responsabilidade civil do médico na prática da distanásia
}

\section{Resumo}

Hodiernamente, a responsabilidade civil médica se caracteriza pela conduta culposa do médico, do nexo de causalidade entre esta e o dano sofrido pela vítima. Tendo por fundamento o paternalismo médico desmedido, muitos pacientes terminais sofrem as consequências da obstinação terapêutica, o que resulta em uma morte sofrida e desumana. Com base nesses pressupostos, procurou-se no presente artigo analisar a responsabilidade civil do médico na prática da distanásia. Para a consecução desse objetivo, além de ter sido realizada uma pesquisa bibliográfica de matérias pertinentes à temática, formulou-se um caso clínico hipotético com o fulcro de melhor nortear a discussão. Disto concluiu-se que há responsabilidade civil do médico pela prática da distanásia, vez que é por meio desta que se instauram danos ao paciente terminal, o que por si só Ihe subtrai o direito a uma morte digna e humana

Palavras-chave: Responsabilidade civil - médicos. Doente terminal. Morte.

\section{Resumen}

\section{Responsabilidad del médico en la práctica de la distanasia}

Actualmente la responsabilidad civil médica se caracteriza por la conducta ilícita del médico, la relación de causalidad entre éste y el daño sufrido por la víctima. Tomando por base un paternalismo médico excesivo, muchos pacientes terminales sufren las consecuencias de la terquedad terapéutica, lo que implica una muerte dolorosa e inhumana. Con base en estos supuestos, intentamos objetivar en este artículo, analizar la responsabilidad del civil del médico en la práctica de la distanasia. Para lograr este objetivo, además de haberse realizado una búsqueda bibliográfica de material relacionado con el tema, se compuso un caso clínico hipotético con el apoyo de mejor orientar a la discusión. Se concluyó que existe responsabilidad civil del médico por la práctica de la distanasia, ya que es a través de este que se establece el daño al paciente terminal, lo que por sí solo le resta el derecho a una muerte digna y humana

Palabras-clave: Responsabilidad civil - médicos. Enfermo terminal. Muerte.

\begin{abstract}
Liability of the physician in the practice of dysthanasia

Medical liability is nowadays characterized by the wrongful conduct of the physician, the causal link between this and the damage suffered by the victim. Having founded on the medical paternalism, many terminally ill patients suffer the consequences of medical futility, which entails in a painful and inhumane death. Based on these assumptions, the article aims to consider the liability of the physician in the practice of futility. To achieve this goal, and with a literature research of relevant material to the issue performed,, a hypothetical clinical case was elaborated to better guide the discussion. It was concluded that there is liability for the practice of medical futility, since it is through this that are established damage to the terminal patient, which alone will subtract the right to a dignified and human death.

Key words: Damage liability - physicians. Terminally ill. Death.
\end{abstract}

1. Mestre cecilia.Iobo@hotmail.com - Centro Universitário Estácio (FIC), Fortaleza/CE, Brasil.

\section{Correspondência}

Rua José Alves Cavalcante, 700, Casa 14-B Cidade dos Funcionários CEP 60822-570. Fortaleza/CE, Brasil.

Declara não haver conflito de interesse. 
O homem, como ser vulnerável a doenças, viuse desde os primórdios dependente de alguém que pudesse cuidar e/ou curar as suas enfermidades. Destarte, as primeiras atividades médicas tinham cunho místico-religioso, sendo a figura do médico representada pelo mago ou sacerdote, o qual fundamentava as suas técnicas curativas em poderes sobrenaturais. Havia, portanto, total desconhecimento acerca da etiologia das doenças e das consequências do tratamento empregado sobre o organismo humano.

Segundo Kriger ${ }^{1}$, o Código de Hammurabi previa amputação das mãos do médico que não obtivesse sucesso nas intervenções cirúrgicas. No antigo Egito, o médico que desrespeitasse a metodologia contida no livro de conduta médica era condenado à morte, independentemente da evolução do quadro clínico do paciente. Em Roma, com o advento da Lex Aquilia, foi possível formular o conceito de culpa a partir de condutas médicas, tais como o abandono de pacientes e a recusa de assistência à prestação médica, bem como erros derivados da imperícia e experiências perigosas. Como consequências desses ilícitos, a Lei Aquilia imputava ao médico a pena de morte ou deportação.

A responsabilidade médica era inicialmente desvinculada da culpa e assumia caráter punitivo, consubstanciado nas penas corporais. À medida que o Direito evoluiu e a Medicina ingressou na cientificidade, a responsabilidade civil do médico assumiu um caráter subjetivo, o que para configurar-se necessitaria identificar a conduta culposa do médico, bem como estabelecer o nexo causal entre essa e o dano sofrido pela vítima. A par dessas considerações, objetivou-se, neste artigo, analisar a responsabilidade civil do médico na prática da distanásia. A metodologia remete a levantamento bibliográfico e análise de caso clínico hipotético, para ilustrar a discussão.

\section{Responsabilidade civil médica e o ordenamen- to jurídico}

Na história brasileira, segundo Kriger ${ }^{1}$, o primeiro diploma legal que previu a responsabilidade dos profissionais ligados à área médica foi o Código Penal de 1890, que estipulou nos artigos 296 e 306 as penas correspondentes aos atos médicos falhos, praticados por imprudência, negligência e imperícia, ou por inobservância de alguma disposição regulamentar. No âmbito civil, o Código Civil de 1916 determinava no art. 1.545 a responsabilidade civil dos médicos, os quais estariam obrigados a reparar o dano sempre que da imprudência, negligência ou imperícia em atos profissionais resultasse a morte, a inabilitação de servir ou o ferimento do paciente.

$\mathrm{O}$ art. 951 do atual Código Civil ${ }^{2}$ regulamenta genericamente a matéria ao determinar que os arts. 948,949 e 950 sejam aplicados nos casos de indenização devida por aquele que, no exercício da atividade profissional, por negligência, imprudência ou imperícia, causar a morte do paciente, agravar-lhe o mal, causar-lhe lesão ou inabilitá-lo para o trabalho. Tal responsabilidade tem como pressuposto normativo o art. 186 e o caput do art. 927, cujos dispositivos concentram o ato ilícito na conduta culposa do agente.

Ainda nesse contexto é válido destacar a diferenciação entre culpa e erro médico. Segundo $\mathrm{Ca}$ valieri ${ }^{3}$, o erro médico será configurado quando a conduta profissional for correta, mas a técnica empregada, não; há uma falha do homem normal, de modo que, para o erro médico ser escusável, além de ter em vista as circunstâncias do caso concreto, deverá também revelar-se vencível à mediana cultura médica. Destarte, haverá imperícia quando a técnica for correta, mas a conduta médica houver sido incorreta - isso supõe falta de diligência ou prudência em relação ao que se espera de um bom profissional.

Além da legislação civilista, a responsabilidade subjetiva do médico ganha resguardo no Código de Defesa do Consumidor (CDC) ${ }^{4}$, que determina, no art. $14, \S 4^{\circ}$, que a responsabilidade desse profissional seja apurada mediante a verificação de culpa. Vale ressaltar que a responsabilidade subjetiva civil do médico defendida pelo $C D C{ }^{4}$ refere-se somente à pessoa do profissional, não favorecendo, portanto, a pessoa jurídica para a qual trabalhe como empregado ou faça parte em sociedade, como descreve Cavalieri ${ }^{3}$. Assim, se vários médicos resolvem constituir uma sociedade, a responsabilidade da entidade jurídica não será subjetiva.

Conforme Miragem ${ }^{5}$, os hospitais e demais instituições privadas de saúde são considerados fornecedores de serviços de saúde, encontrando-se dessa forma sob a égide do art. $3^{\circ}$ do CDC ${ }^{4}$. Como resultado dessa determinação legal, e por força do art. 14 caput do CDC, tais fornecedores respondem por danos causados aos pacientes-consumidores, independentemente de culpa, ou seja, sua responsabilidade é objetiva, pelo que respondem perante aos pacientes à medida que oferecem um serviço defeituoso. Exemplifica a afirmação um caso de agravamento de moléstia por infecção hospitalar. 
Portanto, não basta configurar a conduta culposa do médico para imputar-lhe responsabilidade; é necessário também que a imprudência, a negligência ou imperícia médica causem algum dano ao paciente. $\mathrm{Na}$ visão de Kfouri ${ }^{6}$ os danos médicos indenizáveis podem ser de natureza física, material ou moral. Para o autor, os danos físicos adquirem maior relevância, haja vista ser a atividade médica exercida, em regra, sobre o corpo. Nesse caso, o prejuízo corporal se compõe de elementos variáveis e indenizáveis, separadamente, conforme a invalidez seja parcial ou total, permanente ou temporária.

O autor considera que danos materiais são, em sua maioria, consequências dos danos físicos, incluindo-se o lucro cessante (por deixar de trabalhar temporária ou permanentemente), despesas médico-hospitalares, medicamentos, contratação de outros profissionais de saúde, enfim, todos os gastos relacionados com o dano advindo da conduta médica. Kfouri ${ }^{6}$ finaliza esse argumento aduzindo que os danos morais provenientes da assistência médica são os que advêm da estética corporal comprometida, da dor sofrida e do profundo mal-estar resultante das violações aos direitos da personalidade. É importante ressaltar que alguns autores consideram o dano estético independente do dano moral. Barros ${ }^{7}$ conceitua dano estético como aquele capaz de ensejar um sofrimento psicossocial à forma corporal socialmente aceita, de modo a provocar desgosto, humilhação e vergonha.

Não obstante a culpa e o dano serem necessários para caracterizar a responsabilidade civil do médico, por si sós eles são insuficientes, haja vista exigir a evidência de um liame entre a culpa médica e o dano sofrido pelo paciente, pois dessa forma estarão configurados os pressupostos dessa responsabilidade. Conforme Kfouri ${ }^{6}$, a relação de causalidade entre a conduta e o dano é ainda motivo de discussão no meio doutrinário. Para alguns, essa relação deveria obedecer aos critérios da teoria da equivalência das condições causais, na qual a causa é toda condição que tenha contribuído para o resultado. Outros defendem a apuração, mediante a teoria da causalidade adequada, em que a causa é tida como condição que normalmente deriva para o resultado danoso. Por fim, há os que optam pela teoria da causa própria, na qual a causa é o fator, temporalmente mais próximo, que condiciona o resultado.

Em meio a essa divergência, Cavalieri ${ }^{3}$ afirma que a identificação do nexo de causalidade deverá obedecer aos critérios da teoria da causalidade adequada. Portanto, por seu intermédio poder-se-á identificar a causa adequada como sendo aquela que, de acordo com o curso normal das coisas e a experiência comum da vida, revela-se a mais idônea para gerar o efeito. Assim, para que o paciente-vítima logre êxito em demonstrar a responsabilidade civil médica, é necessário que evidencie a presença dos seus pressupostos, ou seja, a conduta voluntária médica, o dano injusto sofrido (que pode ser patrimonial ou extrapatrimonial) e a relação de causalidade entre o dano e a ação ou omissão médica.

\section{Natureza jurídica da responsabilidade civil médica}

Hodiernamente, não há pensamento unívoco sobre a natureza jurídica da responsabilidade civil médica, haja vista os diferentes modos como se consolida a prestação dos serviços médicos. Assim, essa pode ser tanto contratual como extracontratual, ou seja, a prestação médica pode ser decorrente de contrato previamente estabelecido entre as partes - médico e paciente - no qual o paciente escolhe livremente o profissional médico e o paga pelos seus serviços, como também poderá advir da inexistência de contrato entre as partes, como bem se observa nas circunstâncias da vida, a exemplo de quando o médico socorre um acidentado em via pública.

Essa discussão em torno da natureza da responsabilidade civil do médico tem seu escopo fundamental no aspecto probatório. Conforme Sá e Naves ${ }^{8}$, a carga de prova atribuída às partes é diversa, no que se refere à responsabilidade contratual e extracontratual. Na responsabilidade civil médica contratual, em regra, presume-se a culpa do devedor, na hipótese de inadimplemento do contrato; de tal forma que, nesse caso, basta provar a existência do contrato, o descumprimento da obrigação contratual, o dano e o nexo de causalidade. No que se refere à responsabilidade civil médica extracontratual, deverá o autor demonstrar que o dano é fruto da negligência, imperícia ou imprudência do médico. É importante destacar que, independentemente da natureza jurídica da responsabilidade civil médica, esse profissional estará vinculado a deveres, os quais uma vez descumpridos ensejarão indenização.

Segundo Miragem ${ }^{5}$, esses deveres são agrupados em três categorias a seguir analisadas: 1) os deveres de informação e esclarecimento; 2) os deveres da técnica e perícia; 3 ) os deveres de cuidado, diligência e prudência. 


\section{Deveres de informação e esclarecimento}

Encontram-se positivados no sistema jurídico brasileiro, no que diz respeito às relações de consumo (arts. 31 e 46 do $C D C$ ), resultando no direito comum da incidência do princípio da boa-fé, presente nos arts. 113, 187 e 422 do Código Civil (CC). Dessa forma, a boa-fé deve estar inserida no dever médico de informar ao paciente, com precisão e clareza, os riscos e os benefícios decorrentes de determinado procedimento a que ele irá se submeter, respeitando, com isso, a sua autonomia diante do tratamento proposto. Assim, o direito de autodeterminação do paciente implica no dever de informação do médico.

\section{Deveres da técnica e perícia}

Constituem, em regra, o cerne da caracterização da culpa médica. Requerem, por parte do médico, constante atualização de conhecimentos, dada a evolução das ciências médicas, de modo a empregar a técnica adequada ao tempo da execução do tratamento e, assim, prestar assistência (o mais possível) isenta de erros.

\section{Deveres de cuidado, diligência e prudência}

Exigir do médico o dever de cuidar é obrigá-lo a adotar toda a cautela possível durante o exercício de sua profissão. Por sua vez, o dever de diligência está relacionado com a atenção devida que o médico deverá ter para com o paciente. A prudência impõe ao médico que não adote procedimentos fora dos padrões de conduta técnica médica, bem como não suprima fases de tratamento desvinculadas dos juízos científicos com o intuito de se autofavorecer.

Como se percebe, esses deveres estão implícita ou explicitamente inseridos na relação médico-paciente, de modo a ser irrelevante, nesse caso, identificar a sua natureza jurídica. O certo é que o dano sofrido pelo paciente, advindo do descumprimento de um desses deveres, acarretará para o médico a obrigação de repará-lo.

\section{O objeto da obrigação da prestação de servi- ços médicos}

Muito se discute, hoje, se o objetivo da obrigação médica está restrito unicamente à obrigação de meio, ou se pode também ser caracterizado como de resultado. A questão em torno dessa problemática cinge-se em matéria processual, no que concerne ao ônus probatório. Entretanto, para melhor com- preender essa discussão, faz-se mister individualizar o conceito dessas obrigações.

Segundo Miragem ${ }^{5}$, na obrigação de resultado há comprometimento do devedor com determinado fim, ou seja, há um critério objetivo de identificação do adimplemento ou não da obrigação, que é a realização ou não do resultado devidamente estabelecido pelas partes. Com pertinência à obrigação de meio o autor refere que não há comprometimento do devedor com a obtenção de fim específico, ou seja, de alcançar um resultado predeterminado.

Mediante essas definições torna-se mais fácil identificar o ônus probatório em cada obrigação. Conforme Benacchio ${ }^{9}$, na obrigação de meio o credor (o paciente lesado) deverá provar a conduta ilícita do obrigado - médico -, isto é, se o médico faltou-lhe com atenção, diligência e cuidados adequados durante a prestação de seus serviços. No que se refere à obrigação de resultado, o pacientelesado deverá demonstrar a existência do contrato e seu consequente inadimplemento, ou seja, a não obtenção do resultado estabelecido. Nesse caso, há culpa presumida do médico pelo não cumprimento do contrato, cabendo-Ihe o ônus de provar que o dano foi decorrente de força maior, caso fortuito ou culpa exclusiva da vítima.

Com base nesse raciocínio, a jurisprudência e a doutrina brasileira adotaram como sendo de meio a obrigação assumida pelo médico, isentando-o do dever de atender ao interesse específico do paciente, tendo em vista que o cerne da arte médica está embutido no desempenho do profissional com o máximo de cuidado, diligência e perícia possível em prol da cura do paciente, o que, às vezes, por fatores alheios à sua vontade, não é possível de ocorrer. Contrapondo-se a esse pensamento unívoco, subsiste no Direito brasileiro a determinação de considerar como sendo obrigação de resultado a decorrente de cirurgias plásticas estéticas. No entanto, para meIhor entender esse posicionamento é prudente diferenciar a cirurgia plástica estética e a reparadora.

Conforme Miragem ${ }^{5}$, as cirurgias plásticas, meramente estéticas, são aquelas realizadas com o intuito de embelezar: o paciente se submete a determinada intervenção física de modo a alterar sua aparência, tornando-a mais agradável para si. Nesse caso, o médico assume perante o paciente o compromisso de obter o resultado pretendido. A cirurgia plástica reparadora diz respeito ao procedimento de correção ou reconstituição de deformidades, cicatrizes ou alterações corpóreas, e o profissional não 
tem como assegurar o êxito da operação ou reconstituição física do paciente. Assim, a linha de raciocínio dominante nas jurisprudências é a de considerar a obrigação médica proveniente das cirurgias meramente estéticas como de resultado, já que o médico se compromete a obter, por meio do procedimento, uma finalidade específica do paciente.

Ainda em caráter de excepcionalidade da obrigação de meio, assumida pelos médicos, temse a obrigação de resultado, a que está vinculado o anestesista, como aponta Miragem ${ }^{5}$. Para o autor, o anestesista deverá ao mesmo tempo incumbir-se do adormecimento e do despertar do paciente, bem como assisti-lo na recuperação pós-anestésica. Qualquer anormalidade que vier a causar dano ao paciente importará descumprimento da obrigação pelo profissional, presumindo-se a sua culpa. Logo, não poderá o anestesista alegar o desconhecimento de eventuais reações que o paciente venha a apresentar pela administração de uma droga. Vale ressaltar que esse fato ensejará responsabilidade solidária para o cirurgião, tornando-o também responsável pela obrigação de indenizar.

Diante do exposto, resta reforçar a tese de que a atividade médica não é ciência exata. O êxito da intervenção cirúrgica ou do tratamento proposto dependerá não apenas da técnica, mas também da reação orgânica de cada paciente, bem como dos fatores sociais, econômicos, psicológicos e espirituais em que esteja inserido.

\section{Delimitações da distanásia}

Não há como viver sem, em dado momento, morrer. Vida e morte são fases inerentes do ciclo vital. Mesmo diante dessa irrefutável constatação, celeumas exsurgem, dando azo a inúmeros questionamentos que ultrapassam o cartesianismo jurídico e caminham ao alcance de outras áreas do conhecimento, como a teologia, filosofia, psicologia e a medicina, o que permite constituir dialética interdisciplinar.

O entendimento sobre a morte passou por profundas transformações históricas e sociais. Segundo Áries ${ }^{10}$, a morte, nos século XVIII e início do século XIX, era uma cerimônia pública que ocorria geralmente no âmbito doméstico, em que o próprio moribundo conhecia seu protocolo e, na maioria das vezes, chegava a presidi-lo. Nesse cenário fazia-se importante a presença da família, dos amigos e dos vizinhos. Os ritos da morte eram aceitos com simplicidade e cumpridos numa liturgia cerimonial, mas sem caráter dramático ou com gestos de emoção excessivos.

Ainda para o autor, no decorrer do século XIX se desconstrói essa visão natural da morte, que passa a ser vista com crescente temor, tornando-se vergonhosa e objeto de interdição. Há um esforço enorme em negá-la. Os que cercam o doente terminal tendem a poupá-lo e ocultar-lhe a gravidade de seu estado. A verdade começa a ser problemática. A negação da finitude humana apoia-se, principalmente, no desenvolvimento científico e no avanço tecnológico da medicina.

Com o surgimento dos antibióticos, as doenças infecciosas, antes mortais, passaram a ser perfeitamente curáveis, enquanto doenças crônicas e degenerativas tornaram-se as causas de morte predominantes. A biotecnologia trouxe sofisticados equipamentos de recuperação e preservação das funções vitais, de modo que a morte passou a ser encarada como resultado acidental, como parte dissociada da vida.

Assim, os avanços tecnológicos na área médica e a busca insensata pela imortalidade do ser humano deslocaram o cenário da morte do seio familiar para o ambiente hospitalar, no qual, geralmente, o moribundo é afastado dos seus entes queridos, confinado à dependência de aparelhos e a procedimentos invasivos, rodeado por profissionais que, obstinados pela cura da doença, teimam em prolongar-lhe a chegada da morte, mesmo que essa já seja iminente. A distanásia é esse encarniçamento terapêutico.

Lexicamente, o termo distanásia significa "morte lenta, com grande sofrimento". Com base nessa definição, Pessini ${ }^{11}$ classifica distanásia como sendo a ação, intervenção ou o procedimento médico que não atinge o objetivo de beneficiar a pessoa em fase terminal e que prolonga inútil e sofridamente o processo de morrer, procurando distanciar a morte. Ressalta o autor que, nessa conduta, não se prolonga a vida, propriamente dita, mas tão somente o processo de morrer.

Infere-se, do conceito acima, que a distanásia está intrinsecamente relacionada com o emprego de terapêutica fútil ao enfermo terminal, haja vista ser esse a vítima maior dessa prática médica desumana. Mas, afinal, o que se entende por paciente terminal? Gutierrez ${ }^{12}$ oferece resposta a essa pergunta ao afirmar que a identificação do paciente terminal está vinculada à evidência de terem sido esgotadas as possibilidades de resgate à saúde do doente, de modo que a possibilidade de morte próxima parece inevitável e previsível. O enfermo torna-se, pois, 
irrecuperável, e caminha para a morte, sem que consiga reverter essa caminhada.

Das delimitações expostas, percebe-se que a distanásia está longe de defender o direito à vida, haja vista identificar o ser humano a um mero objeto da ciência médica. Tal argumento advém do fato de que a atual Constituição brasileira ${ }^{13}$ contempla o direito à vida, à luz de outros valores superiores, como o da dignidade da pessoa humana. Viver é um bem tido como básico fundamental, porém não conduz ao entendimento de que seja absoluto ou preservado a todo custo. "Viver" sob a tortura, mesmo que seja a tortura de uma terapia fútil, nada mais é do que anular o caráter humano do paciente: é, simplesmente, coisificá-lo.

Nessa linha, Dworkin ${ }^{14}$ afirma que as pessoas às quais se nega a dignidade podem perder o amorpróprio que ela protege, e tal recusa, por sua vez, faz com que mergulhem em uma forma ainda mais terrível de sofrimento: o desprezo e a aversão que passam a sentir por si próprias. Contrapondo-se à perda da dignidade do doente durante o seu processo de morrer, o atual Código de Ética Médica (CEM) fundamentou os incisos VI e XXII do Capítulo I - Princípios Fundamentais:

VI - O médico guardará absoluto respeito pelo ser humano e atuará sempre em seu benefício. Jamais utilizará seus conhecimentos para causar sofrimento físico ou moral, para o extermínio do ser humano ou para permitir e acobertar tentativa contra sua dignidade e integridade.

XXII - Nas situações clínicas irreversíveis e terminais, o médico evitará a realização de procedimentos diagnósticos e terapêuticos desnecessários e propiciará aos pacientes sob sua atenção todos os cuidados paliativos apropriados ${ }^{15}$.

Esses incisos foram, sem dúvida, um grande passo para que o médico reconheça a sua falibilidade ante a finitude humana. Não que esse profissional se torne omisso frente ao dever de cuidar, mas que a sua atuação seja voltada para cuidados paliativos que priorizem as necessidades básicas do paciente, incluindo as biológicas, as psicológicas e espirituais, de modo a tornar o processo-morte menos doloroso e mais digno possível. Ser paciente terminal não significa ser um resíduo biológico no ambiente hospitalar. $\mathrm{O}$ doente, mesmo diante de sua terminalidade, é acima de tudo ser humano e, portanto, titular de seus direitos, motivo pelo qual a inviolabilidade de sua dignidade deve ser resguardada até o seu último suspiro.

\section{A responsabilidade civil médica ante a prática da distanásia}

Neste artigo, em momentos anteriores foram discutidas duas temáticas bem distintas. No primeiro, permitiu analisar a responsabilidade civil do médico sob a ótica da legislação pátria. No segundo, sob os argumentos médicos e bioéticos, delimitouse a distanásia, o seu conceito, bem como suas consequências para o paciente terminal.

Segundo Gifoni ${ }^{16}$, nada impede que o médico seja responsabilizado civilmente, por desrespeito à autonomia do paciente terminal e o desejo de sua família, por lhes ter proporcionado grande desconforto físico e moral. Acrescenta o autor que o art. 15 do CC não se aplica aqui, em defesa do médico, haja vista que a situação de risco de vida do doente terminal não é, não foi, nem jamais será alterada por qualquer ato médico, justo por ser condição sine qua non de sua doença, que o acompanhará até o último dia de vida. Benacchio ${ }^{9}$ afirma que não há dúvidas quanto ao fato de ser vedado ao médico impor ao paciente tratamento excessivamente doloroso e ineficaz, e também da ausência do dever de salvar a vida de doente terminal para cuja doença não há cura conhecida.

A par dessas informações, formulou-se um caso clínico hipotético, com o intuito pedagógico de evidenciar a prática da distanásia, bem como de identificar os pressupostos caracterizadores da responsabilidade civil médica. Embora o delineamento do caso hipotético não decorra - a rigor - de processo de pesquisa ou observação, congrega elementos conjecturais atinentes à prática clínica. Assim, a produção deste caso clínico como instrumento didático favorece a reflexão sobre conflitos correlatos, tanto para estudantes quanto para profissionais.

\section{Caso clínico}

Sr. X, 64 anos, médico, portador de uma neoplasia gástrica avançada, com metástases pulmonares, hepáticas e renais, sem indicações de quimioterapia e radioterapia, procura um hospital sentindo fortes dores abdominais e moderada dispneia. No momento de sua admissão, estando clinicamente consciente e ciente de sua terminalidade, expressa, perante o médico assistente, o desejo de permanecer sob os cuidados paliativos e na companhia de sua família, bem como de não ser transferido para a UTI quando de uma eventual piora clínica e/ou parada cardiorrespiratória. No segundo dia de internação, o sr. X, na presença do médico assistente e de 
seus familiares, tem uma parada cardiorrespiratória. Nesse momento, o profissional, não levando em conta a vontade do paciente e de sua família, realiza as manobras de ressuscitação cardiopulmonar e encaminha o paciente para a UTI. O sr. X permanece assim atrelado a vários tubos, submetendo-se a diversos procedimentos invasivos; o seu corpo passa a ser apenas uma extensão das máquinas. A família, inconformada com o desprezo da vontade final do doente, reza para que Deus o remova daquela tortura. Depois de uma semana de internação na UTI, o sr. $X$ vai a óbito em um ambiente solitário e frio, sem ter a oportunidade de se despedir daqueles que o amavam. Seu corpo flagelado acabou repousando "empacotado" sobre uma maca hospitalar.

Da análise do caso supracitado ficou evidente a prática da distanásia, confirmada à medida que o médico assistente, mesmo diante da terminalidade do paciente, realizou medidas heroicas que culminaram com o emprego de terapia fútil. A morte desse enfermo já era tida como realidade próxima e nenhum tratamento iria reverter a progressão de sua doença. A obstinação terapêutica falou mais alto do que a autonomia do paciente, privando-o de morrer de maneira humanizada e digna. No caso clínico descrito, no qual o procedimento empregado pode ser caracterizado como distanásia, foi possível identificar os seguintes pressupostos da responsabilidade civil médica: conduta culposa, dano e nexo causal.

\section{Conduta culposa}

Como evidenciado inicialmente, a responsabilidade civil pessoal do médico é subjetiva, tendo a culpa como componente intrínseco do ato ilícito. Para Cavalieri ${ }^{3}$, a culpa se caracteriza pela infração do dever ou diligência de cuidar. $A$ inobservância desse dever de cuidado torna a conduta culposa. $A$ par disso, exprime um juízo de reprovação sobre a conduta do agente, por ter violado o dever de cuidado quando, ante as circunstâncias específicas do caso, deveria e até poderia ter agido de outro modo. Ressalta ainda o nobre doutrinador que a falta de cautela, diligência, atenção e cuidado são o substrato final da culpa. Implícita nessa afirmação está a caracterização da imprudência como sendo a falta de cautela ou cuidado por conduta comissiva, positiva, por ação; a negligência como a mesma falta de cuidado por conduta omissiva e a imperícia como decorrente da falta de habilidade no exercício de atividade técnica, caso em que se exige, de regra, maior cuidado ou cautela do agente.

À luz desses fundamentos doutrinários podese afirmar que o médico, cuja conduta ensejou a distanásia, incorreu na imprudência e na imperícia. Senão vejamos: o seu comportamento foi, no mínimo, imprudente, à medida que sua ação cercou-se de impetuosidade, além de desprovida de cautela, pois, mesmo diante do conhecimento do quadro clínico do doente e de sua vontade, agiu com o paternalismo, submetendo-o a tratamento fútil, cujo único escopo foi o de prolongar seu sofrimento e morte. Complementado esse argumento, destaca-se o posicionamento de Kretzmann ${ }^{17}$ sobre o paternalismo médico. Ao expressar a ideia de Clotet o autor afirma que a relação paternalista médico-paciente caracteriza-se por um desequilíbrio, em que o cuidado prestado anula a pessoa objeto do mesmo, favorecendo a passagem desapercebida do saber ao poder, com consequências lamentáveis, pois a pessoa chega a ser apagada como individualidade singular.

Como se não bastasse essa imprudência, o médico em questão foi também imperito, haja vista ter empregado meios de uso não habitual e contraindicados na assistência ao paciente terminal. Tal explicação tem como fundamento a literatura médica, que enfatiza, unanimemente, que a conduta técnica a ser adotada pelo médico na assistência ao enfermo terminal deve ser aquela voltada para os cuidados paliativos, capazes de proporcionar ao doente um cuidado humanizado e uma morte digna.

Com o intuito de evitar imperícia dessa ordem, o atual CEM ${ }^{15}$ dispôs, no capítulo destinado à relação dos médicos com os pacientes e familiares, o parágrafo único do art. 41, que enfatiza que nos casos de doença incurável e terminal, deve o médico oferecer todos os cuidados paliativos disponíveis sem empreender ações diagnósticas ou terapêuticas inúteis ou obstinadas, levando sempre em consideração a vontade expressa do paciente ou, na sua impossibilidade, a de seu representante legal. Ao falar sobre distanásia e a dignidade do paciente, Sertã ${ }^{18}$ valeu-se das palavras de Pessini para expressar que a responsabilidade do médico não se limita a sustentar a vida, mas abarca também o dever de oferecer cuidados paliativos, no momento em que manter a vida não é considerado mais razoável. Manter a vida no curso de uma doença terminal deixa de ser objetivo principal, razão pela qual o alívio e os cuidados humanos passam a ser as preocupações exclusivas.

Ante tais argumentos a imprudência e a imperícia médica são ratificadas no caso da distanásia, levando-se em conta a obstinação terapêutica que conduz o paciente terminal a um tratamento desumano e doloroso. 


\section{Dano}

Conforme descrito, os danos médicos podem ser de natureza física, material ou moral. Com relação aos danos físicos, eles estão atrelados às consequências da atividade médica sobre o corpo humano. Dessa afirmação não é difícil perceber que o paciente-vítima da distanásia sofreu todas as iatrogenias possíveis, pois a terapêutica ali empregada não conduziu à sua cura, mas tão somente à decomposição corpórea. Quanto aos danos materiais, esses implicam em despesas médico-hospitalares, medicações, contratação de outros profissionais de saúde, enfim, gastos relacionados ao dano advindo da conduta médica.

No tocante ao dano moral sofrido pelo paciente terminal, vítima da distanásia, ressalta-se o posicionamento de Maria Celina Bodin de Moraes ${ }^{19}$. Segundo ela, constitui dano moral a lesão a qualquer dos aspectos componentes da dignidade humana, quais sejam, o princípio da igualdade, da integridade psicofísica, da liberdade e da solidariedade. $\mathrm{O}$ fato de submeter o paciente terminal ao mesmo procedimento médico destinado ao enfermo, com possibilidades de cura, implica desconsiderar a condição de desigualdade do doente terminal, o que leva à violação do princípio da igualdade sob o aspecto material.

O respeito à condição clínica desse paciente remete à adoção de uma assistência não direcionada para a cura, mas sim para os cuidados paliativos que transformem o processo-morte desse doente em algo mais humano e dignificador. $O$ tratamento fútil, advindo da internação na UTI, proporcionou severa violação à integridade psicofísica do paciente terminal, impossibilitando-o de exercer o direito a uma existência digna. Tal fato logrou vitimar o doente terminal a procedimentos médicos invasivos, que desvinculados de uma finalidade curativa proporcionou-lhe apenas o prolongamento de sua morte e o isolamento daqueles que realmente o amavam.

No que se refere à liberdade, essa foi frontalmente atingida, vez ter cerceado a autonomia do paciente. Autonomia significa autogoverno, autodeterminação da pessoa ${ }^{20}$ para tomar decisões que afetam sua vida, saúde e integridade físico-psíquica nas relações sociais, de modo que o exercício da autonomia implica ser livre de coações externas e internas para fazer escolhas dentre as opções apresentadas. Decorre desta definição de Costa, Oselka e Garrafa ${ }^{20}$ que o respeito à autonomia implica reconhecer que ela tem o direito de deliberar e tomar decisões segundo seu próprio plano de vida, embasado em crenças, aspirações e valores próprios, ainda que divergentes daqueles dominantes na sociedade ou dos que são aceitos pelos profissionais de saúde.

Complementado esse posicionamento, tornam-se relevantes as palavras de Sarlet ${ }^{21}$ sobre a autonomia da vontade de Kant. Para este, o homem é o único ser capaz de orientar suas ações a partir de objetivos racionalmente concebidos e livremente desejados. A dignidade do ser humano consiste, pois, em sua autonomia, que é a aptidão para formular as próprias regras da vida, ou seja, a sua liberdade individual ou o seu livre arbítrio. Nesse contexto, o atual CEM ${ }^{13}$ expôs, no Capítulo IV - Direitos Humanos, os seguintes artigos:

É vedado ao médico:

Art. 24. Deixar de garantir ao paciente o exercício do direito de decidir livremente sobre sua pessoa ou seu bem-estar, bem como exercer sua autoridade para limitá-lo.

Art. 28. Desrespeitar o interesse e a integridade do paciente em qualquer instituição na qual esteja recolhido, independentemente da própria vontade.

Infere-se que o paciente terminal, clinicamente consciente e ciente do seu prognóstico, tem o direito à liberdade de escolher uma morte mais humanizada e na presença dos seus entes queridos. Ignorar a autonomia desse paciente é, portanto, negar a sua condição humana, é violar a sua personalidade e, consequentemente, faltar com respeito à sua dignidade.

\section{Nexo causal}

Não há como deixar de evidenciar o liame entre a conduta culposa do médico e os danos sofridos pelo paciente-vítima da distanásia. No caso desse paciente, sabe-se que o óbito era fato certo e previsível, porém os danos advindos de uma morte desumana tiveram sua origem na conduta culposa do médico, haja vista que se houvesse sido respeitada a autonomia do doente e, por extensão, se o desejo de seus familiares tivesse merecido atenção, nada disso teria ocorrido.

\section{Considerações finais}

Por muito tempo predominou o paternalismo hipocrático no exercício da medicina. Respaldandose em seu conhecimento o médico fazia valer a sua 
vontade diante da autonomia do paciente, sob o pretexto de fazer-lhe o bem. Hoje, a supremacia do princípio da dignidade da pessoa humana, que reconhece o indivíduo como um fim em si mesmo, impede a manutenção do paradigma paternalista, que ignora a autonomia do doente.

O médico que desconsidera a autonomia do paciente terminal, que o submete à prática de uma terapêutica fútil, incorre no dever de reparar os danos provenientes dessa obstinação, que cerceia o direito do doente de escolher uma morte digna e humana para si. Dessa forma, neste primeiro momento, fica evidente a responsabilidade civil médica diante da prática da distanásia. Contudo, os pressupostos processuais desta e a sua efetivação jurídica à parte prejudicada serão objetos de uma discussão a posteriori.

Dos pressupostos caracterizadores da responsabilidade civil do médico, todos se fizeram presentes no exemplo simples, selecionado à guisa de ilustração. A imprudência e imperícia tipificaram a conduta culposa do médico, dado ter agido de forma impetuosa e desprovida de habilidades no tratamento condizente ao paciente terminal, submetendo-o à terapia fútil, em desacordo com a técnica em- pregada àqueles que não têm prognóstico de cura.

O dano se consubstanciou na violação do princípio da igualdade, haja vista ter conduzido o paciente terminal à mesma terapia destinada àqueles que têm possibilidades de cura, ignorando a sua condição de desigualdade, que requeria um tratamento diverso, ou seja, um tratamento centrado nos cuidados paliativos. $O$ dano emergiu também da violação à integridade psicofísica do paciente, bem como do cerceamento à sua liberdade individual, repercutindo, assim, diretamente na sua autonomia e consequentemente na perda de sua dignidade, haja vista não ter sido considerado um fim em si mesmo, mas tão somente meio para satisfazer a vontade paternalista do médico. $O$ nexo de causalidade esteve presente, uma vez que os danos advindos da terapia fútil e a lamentável morte desumana do paciente foram decorrentes da conduta culposa do profissional.

Diante dessas constatações, evidencia-se que a responsabilidade civil do médico, na prática da distanásia, não é mera falácia. Constitui, isto sim, fato concreto que pode culminar com a imputação ao profissional do dever de reparar os danos sofridos pelos pacientes e seus familiares, que em momento de dor e aflição têm sua dignidade maculada.

\section{Referências}

1. Kriger Filho DA. A responsabilidade civil médica frente ao ordenamento jurídico atual. Revista Forense. 2005;380:33-46.

2. Brasil. Código Civil: Lei $n^{\circ}$ 10.406, de 10 de janeiro de 2002. $2^{\mathrm{a}}$ ed. São Paulo: Atlas; 2005.

3. Cavalieri Filho S. Programa de responsabilidade civil. $8^{a}$ ed. São Paulo: Atlas; 2008.

4. Brasil. Código de proteção e defesa do consumidor: Lei n 8.078 , de 11 de setembro de $1990.15^{\text {a }}$ ed. São Paulo: Saraiva; 2005.

5. Miragem B. Responsabilidade civil médica no direito brasileiro. Revista de Direito do Consumidor. 2007;16(63):52-91.

6. Kfouri Neto M. Responsabilidade civil do médico. 6ª ed. São Paulo: Ed. Revista dos Tribunais; 2007.

7. Barros Júnior EA. A responsabilidade civil do médico: uma abordagem constitucional. São Paulo: Atlas; 2007. p. 233.

8. Sa MFF, Naves BTO. Manual de biodireito. Belo Horizonte: Del Rey; 2009.

9. Benacchio M. Responsabilidade civil do médico: algumas reflexões. In: Nery RMA, Donnini RF, coordenadores. Responsabilidade civil: estudos em homenagem ao professor Geraldo Camargo Viana. São Paulo: Ed. Revista dos Tribunais; 2009. p. 320-49.

10. Ariès P. História da morte no Ocidente. Rio de Janeiro: Ediouro; 2003.

11. Pessini L. Distanásia: até quando prolongar a vida? $2^{2 a}$ ed. São Paulo: Loyola; 2007.

12. Gutierrez PL. O que é paciente terminal? Rev Assoc Med Bras. 2001;47(2):92.

13. Brasil. Constituição da República Federativa do Brasil. Brasília: Senado Federal; 1988.

14. Doworkin R. Domínio da vida: aborto, eutanásia e liberdades individuais. São Paulo: Martins Fontes; 2003.

15. Conselho Federal de Medicina. Resolução CFM n 1.931 , de 17 de setembro de 2009. Aprova o Código de Ética Médica. [Internet]. [acesso maio 2011]. Disponível: http://www.portalmedico. org.br/resolucoes/CFM/2009/1931_2009.pdf

16. Gifoni JMM. Ética e questões legais em RPC - responsabilidade civil e penal. [Internet]. Rio de Janeiro: Sociedade de Anestesiologia do Estado do Rio de Janeiro; 2006 [acesso 15 maio 2011]. Capítulo 153, Medicina perioperatória. Disponível: http://www.saj.med.br/uploaded/File/ novos_artigos/153.pdf

17. Kretzmann C G. O princípio da beneficência e o da autonomia e a responsabilidade civil do médico. Revista Trabalho e Ambiente. 2006;4(7):137-54.

18. Sertã RLC. A distanásia e a dignidade do paciente. Rio de Janeiro: Renovar; 2005. p. 154. 
19. Moraes MCB. Danos à pessoa humana: uma leitura civil-constitucional dos danos morais. Rio de Janeiro: Renovar; 2003.

20. Costa SIF, Oselka G, Garrafa V, coordenadores. Iniciação à bioética. Brasília: Conselho Federal de Medicina; 1998.

21. Sarlet IW. Dignidade da pessoa humana e direitos fundamentais na constituição federal de 1988. 8 a ed. Porto Alegre: Livraria do Advogado; 2010.

Recebido: 13.11 .2012

Revisto: 27. 5.2013

Aprovado: 24.6 .2013 